\title{
Migración marítima irregular y gestión de la acogida en Canarias
}

Elaborado por Vicente Manuel Zapata Hernández

Canarias inicia un nuevo ciclo de intensa afluencia migratoria por vía marítima coincidiendo en el tiempo con el desarrollo de la actual pandemia por coronavirus. Las llegadas irregulares se han multiplicado contando en el archipiélago con un sistema de acogida insuficiente y muy debilitado, después de una década de escasa incidencia de esta movilidad a través de la ruta atlántica, que ahora adquiere renovado protagonismo e incorpora una mayor diversidad de perfiles vulnerables en las siempre peligrosas expediciones.

La respuesta institucional ha tenido que enfrentar una mayor complejidad, condicionando la permanente urgencia la adopción de soluciones incompletas e inapropiadas en determinados casos, según refieren muchas de las valoraciones realizadas. El proceso migratorio sigue su curso y cada vez más voces demandan la definición de una adecuada estrategia de acogida, basada en un modelo que integre asimismo los principios de la interculturalidad y se construya mediante la confluencia de todos los actores implicados.

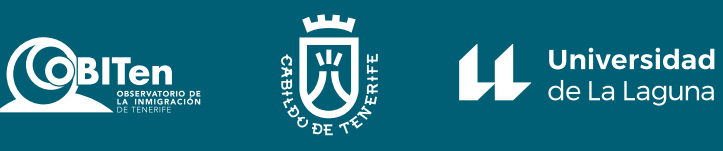




\section{Introducción}

Canarias es referencia de las migraciones internacionales desde hace décadas, convirtiéndose esa movilidad y sus efectos en un hecho estructural de su realidad cotidiana: el 20,2\% de su población había nacido en otro país según el empadronamiento a 1 de enero de 2021 (ISTAC, datos provisionales), 438.230 personas (el 51,6\% son mujeres), cifra que casi triplica la registrada veinte años atrás, lapso de tiempo en el que la aportación de origen extranjero supone las tres cuartas partes del crecimiento demográfico regional. Un flujo continuado y diversificado de personas que eligen las islas para su asentamiento por un amplio conjunto de motivaciones, siendo predominantes las económicas y las residenciales. Una cuestión siempre presente en la agenda social y política del archipiélago, que asimismo despierta interés en los medios de comunicación, sobre todo cuando se relaciona con algunos de los principales problemas de las islas. Es la corriente migratoria predominante, aunque la más visible sea la que tiene una importante componente de tránsito y se expresa a través de la llegada de embarcaciones que pretenden salvar el brazo de mar que nos separa de las costas africanas.

Nos referimos a la migración marítima irregular, documentalmente presente en el archipiélago desde 1994, cuando se apunta a las primeras personas que arriban en una barquilla a la isla de Fuerteventura. Desde entonces se han registrado 135.474 llegadas o interceptaciones en alta mar o cerca del litoral en distintos tipos de embarcaciones, hasta el 29 de agosto de 2021, según los datos del Ministerio del Interior. Con una etapa de importante y prolongada intensidad durante la primera década del presente siglo; y un episodio culminante, centrado en 2006, que ha quedado en la memoria colectiva como la crisis de los cayucos. Es la denominada ruta atlántica o canaria o africana occidental, entre las que conectan el continente africano con los territorios europeos más próximos, bien continentales o insulares en el caso de Canarias u otras islas y archipiélagos mediterráneos (Godenau y Buraschi, 2018).

Se trata de una migración cada vez más conocida por haber sido estudiada y atendida a través de los medios de comunicación, narrada ampliamente por sus protagonistas, cuya expresión implica a un gran número de actores de distinta naturaleza (personas, organizaciones, instituciones, etc.), tanto en las áreas de origen como en las de tránsito y destino. De ahí su complejidad y la de gestionar desde eventos o experiencias aisladas hasta procesos migratorios más amplios y dilatados en el tiempo, tanto por su propia configuración como por el contexto en el que se desarrollan en cada momento. Buena muestra de ello es la progresiva activación de la ruta canaria desde 2018 y su episodio culminante en cuanto a intensificación de 2020, en pleno marco de propagación de la pandemia debida al virus SARS-CoV-2. Episodio que sigue su curso, puesto que las cifras que se van contabilizando no señalan todavía el debilitamiento de la corriente más reciente ${ }^{1}$.

Como antes se señaló, se trata de una vertiente de las migraciones internacionales bastante analizada, centro de interés permanente del propio Observatorio de la Inmigración de Tenerife (OBITen) en algunas de sus publicaciones, que recogen los resultados de investigaciones sobre la inmigración irregular (Godenau y Zapata, 2005 y 2007), el nexo fronterizo Sur-Sur (Godenau y León, 2012) o la movilidad en el marco de las Regiones Ultraperiféricas de la Unión Europea (Asín y Godenau, 2014). La última etapa asimismo ha recibido cum-

1 En el momento de conclusión de este texto, a comienzos del último cuatrimestre de 2021, las cifras de llegadas del año en curso más que duplican a las del precedente: 9.255 frente a 3.925, un $136 \%$ superiores, entre los meses de enero y agosto (243 frente a 131 embarcaciones), según expresa la información del Ministerio del Interior del Gobierno de España. Cabe añadir una importante secuencia de naufragios y muertes en distintas localizaciones del área en que se desenvuelve la ruta. 
plida atención analítica, a través de dos estudios monográficos breves que han intentado contextualizar la ruta canaria en un entramado mucho más amplio y complejo de itinerarios (Godenau y Buraschi, 2018), y adentrarse en las claves para entender el más reciente proceso de intensificación migratoria en su fase inicial (Godenau, Buraschi y Zapata, 2020).

En la mayor parte de estos trabajos se aborda la interpretación general del proceso migratorio, sin adentrarse en lo que ocurre cuando sus protagonistas superan las primeras fases o lapso de tiempo en que son recibidos, atendidos y documentados. La acogida propiamente dicha, esto es, la estancia que comienza con posterioridad, sobre todo la que implica un periodo de tránsito que luego se suele completar con la salida de las islas, ha sido menos estudiada y por lo tanto siguen siendo poco conocidas algunas de sus características esenciales. Una etapa que además ha incorporado novedades en esta última secuencia de intensificación, particularmente desde los meses finales de 2020, reactivando asimismo el interés por las condiciones en las que se encuentran las personas migrantes en situación irregular durante su estancia en Canarias.

Este documento ahonda en esa etapa a través de la experiencia que se desarrolla tras el ascenso más reciente de las llegadas por mar, que junto a sus determinantes será expuesta en la primera parte del análisis. Luego se centrará en la respuesta institucional que se ha articulado como reacción a la nueva situación, considerando además el marco que establece la evolución de la COVID-19. Más adelante se esboza la diversa reacción que se ha derivado de la respuesta ofrecida y sus consecuencias más inmediatas, terminando con un conjunto de conclusiones a modo de claves que permitan superar los elementos menos favorables de un proceso que ha tenido luces y sombras, a juicio de las muchas personas que lo han analizado desde distintas ópticas. Ahora con más perspectiva, parece buen momento para exponer lo sucedido y revisarlo de manera crítica.

\section{Reactivación de la ruta atlántica en un marco de complejidad global}

Ya en publicaciones contrastadas de 2019 se miraba a 2018 como un año de "repunte incipiente" en la ruta atlántica (Godenau, 2019: 161) y se enfatizaba el objetivo de conjugar una adecuada acogida de las personas migrantes y solicitantes de protección internacional, con el de "prevenir, controlar y ordenar los flujos migratorios irregulares en las fronteras" (Zapata, 2019: 238). Insistiendo incluso antes en el enorme reto que supone la acogida cuando "las llegadas tienen una evolución volátil en el tiempo y no se cuenta con infraestructuras fijas para tales tareas" (Godenau y Buraschi, 2018: 2), demandando más atención a la gestión de los flujos migratorios y sus implicaciones, particularmente en territorios insulares y además fronterizos en el área de contacto entre la Unión Europea y el continente africano. Se entiende, además, que la experiencia migratoria ya acumulada y el tratamiento de determinados episodios excepcionales, deben ser la fuente de inspiración para articular respuestas adaptadas a circunstancias exigentes que asimismo suelen ser cambiantes.

Como cambiante ha sido la incidencia de las diferentes rutas migratorias que facilitan el acceso a la Unión Europea desde su entorno más próximo en los últimos años. FRONTEX identifica siete rutas principales ${ }^{2}$ que han registrado casi medio millón de detecciones o interceptaciones entre enero de 2018 y junio de 2021, siendo la cuenca mediterránea el

2 Publicación de FRONTEX a partir de los datos notificados mensualmente por los Estados miembros de la Unión Europea y los países asociados a Schengen, agregados según rutas, sobre "la detección de personas en cruces fronterizos ilegales" (BCPs). Base de datos consultada el 15-08-2021. https://migration-demography-tools.jrc.ec.europa.eu/catalogue/dataset/ds00032 
marco geográfico que mayor peso muestra en el conjunto, sobre todo en sus extremos oriental (Chipre, Grecia en sus fronteras marítimas y terrestres, junto a Bulgaria en sus conexiones con Turquía) y occidental (fronteras marítimas y terrestres españolas excluyendo a Canarias). En el periodo considerado, el protagonismo ha ido pasado de las citadas anteriormente a los itinerarios que implican las fronteras marítimas de Italia y Malta, más los territorios de interacción en la región de los Balcanes, incorporando a Grecia, Bulgaria, Rumanía, Hungría y Croacia.

La ruta canaria o africana occidental despunta principalmente entre septiembre de 2020 y enero de 2021, convirtiéndose durante los meses de octubre y noviembre en la de acceso preferente a la Unión Europea ${ }^{3}$. De ser una puerta de entrada casi marginal o con escasa importancia durante casi una década, después de lo acontecido alrededor de 2006, en poco tiempo adquiere una renovada relevancia, agrupando el 7,1\% de las detecciones totales en el periodo analizado (el 11,7\% si el intervalo se reduce desde agosto de 2019), tal y como puede observarse en la tabla 1 y en el gráfico 1. "Un complejo entresijo de factores", siguiendo a Godenau (2019: 158), explican habitualmente ese cambio de protagonismo, más o menos dilatado en el tiempo, desde el impulso derivado de circunstancias estructurales y coyunturales en las áreas de origen, hasta la impermeabilidad relativa del conjunto de itinerarios, así como el papel que pueden llegar a desempeñar "los intermediarios", entre otros.

Tabla 1

Detecciones en cruces fronterizos ilegales en la Unión Europea según rutas entre 2018 y 2021.

Los datos de 2021

\begin{tabular}{l|c|c|c|c|c|c}
\hline Ruta & 2018 & 2019 & 2020 & 2021 & TOTAL & $\%$ \\
\hline Balcanes Occidentales & 5.844 & 15.127 & 26.918 & 18.910 & 66.799 & 13,9 \\
\hline Mediterráneo Oriental & 56.560 & 83.333 & 20.280 & 7.932 & 168.105 & 35,0 \\
\hline Mediterráneo Central & 23.485 & 14.003 & 35.673 & 23.099 & 96.260 & 20,0 \\
\hline Mediterráneo Occidental & 56.245 & 23.969 & 17.228 & 6.139 & 103.581 & 21,6 \\
\hline África Occidental & 1.323 & 2.718 & 23.029 & 6.953 & 34.023 & 7,1 \\
\hline Circular de Albania a Grecia & 4.550 & 1.944 & 1.365 & 595 & 8.454 & 1,8 \\
\hline Fronteras Orientales & 1.029 & 642 & 615 & 971 & 3.257 & 0,7 \\
\hline Mar Negro & 0 & 2 & 0 & 0 & 0 & 0,0 \\
\hline Otras & 0 & 3 & 2 & 0 & 5 & 0,0 \\
\hline Total & 149.036 & 141.741 & $\mathbf{1 2 5 . 1 1 0}$ & $\mathbf{6 4 . 5 9 9}$ & $\mathbf{4 8 0 . 4 8 6}$ & $\mathbf{1 0 0 , 0}$ \\
\hline
\end{tabular}

Lo cierto es que, en esta última etapa, el acceso a la Unión Europea a través de la España continental y la insular se ha ido equilibrando enormemente, en el segundo caso utilizando sobre todo la conexión a través de Canarias. Circunstancia esencial para estimar la atención y asignación de recursos en la gestión de esta afluencia, añadiendo la complejidad que ofrece el seguimiento de la movilidad humana en un área tan extensa y difícil de controlar como la franja costero-marítima que se extiende por el África occidental desde el sur de Marruecos en sentido meridional, incluso alcanzando en determinadas oportunidades las costas de Guinea a casi 2.500 kilómetros del archipiélago (IOM, 2021).

3 Puede encontrarse información de interés sobre la ruta atlántica desde el África Occidental hasta Canarias en el trabajo de Rojo Esteban (2008), particularmente desde la perspectiva del control de fronteras y la actuación de los cuerpos y fuerzas de seguridad del Estado. 


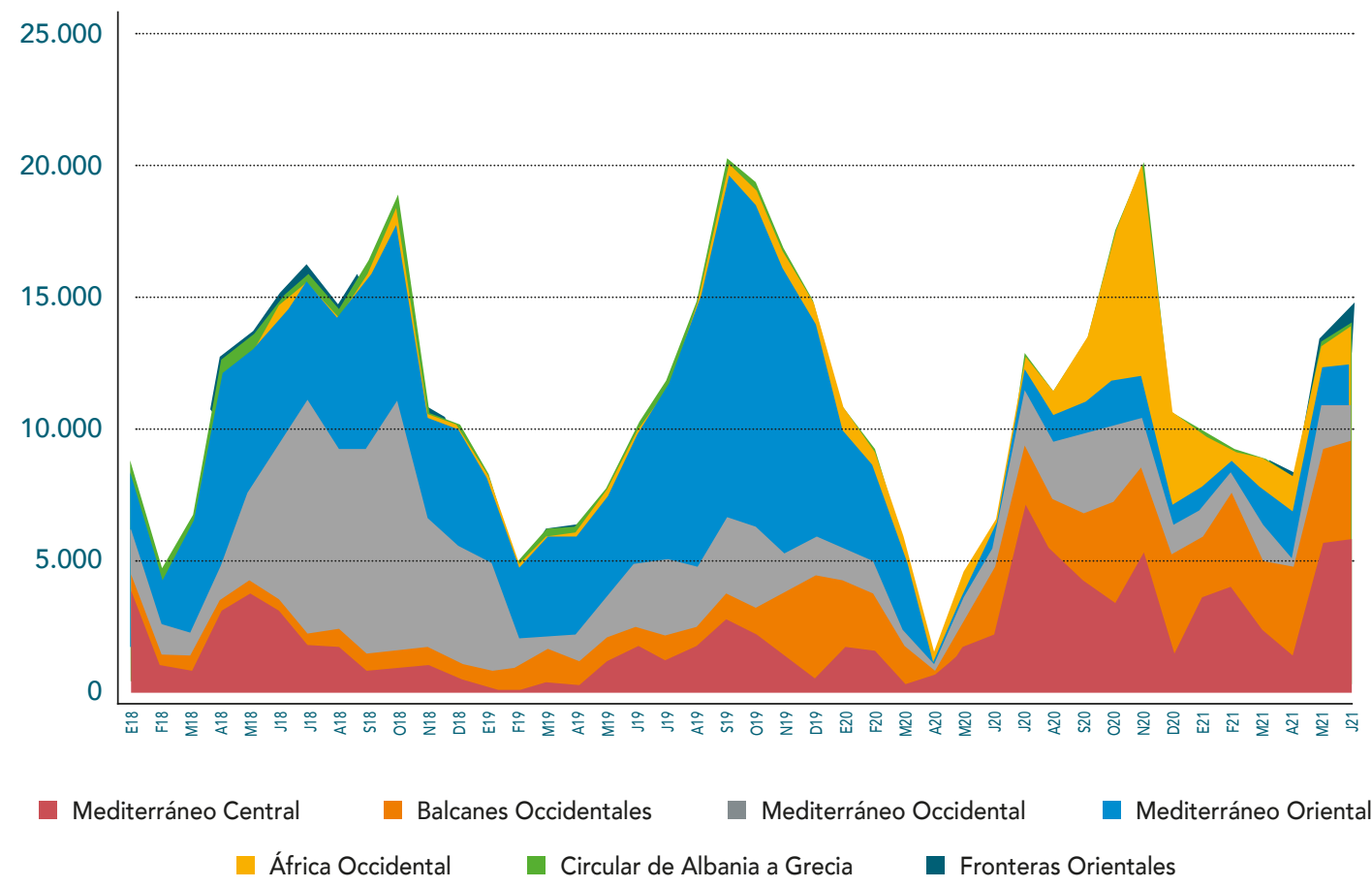

Ya en 2020, las llegadas a Canarias fueron superiores a las peninsulares incluyendo Baleares (23.023 frente a 16.610) y en 2021 van a la par (9.255 y 9.075, hasta el 29 de agosto). En el caso de las islas atlánticas, con expediciones más numerosas (menos embarcaciones) y distancias bastantes más largas cuando los cayucos parten de Mauritania, Senegal, Gambia, Guinea Bissau o Guinea. De hecho, el número medio de personas por embarcación ha ido ascendiendo en el archipiélago canario de 19 en 2018 a 38 en 2021 (es de 30 en todo el periodo considerado, frente a la media de 20 del resto del Estado, esto es, Península, Baleares, Ceuta y Melilla). Con todo, las personas de nacionalidad marroquí concentran el 52,1\% de las llegadas en 2020, a mucha distancia de senegalesas (19,7\%) y malillenses (17,9\%), según publica el Defensor del Pueblo (2021: 25) con datos del Ministerio del Interior. La misma fuente destaca la mayor concentración de esta afluencia en la provincia de Las Palmas (82,3\%), mediante acceso directo o por el traslado que realizan los dispositivos de salvamento tras interceptar las embarcaciones todavía en el mar.

No obstante, en estos últimos tres años y medio la presencia de migrantes de procedencia subsahariana es mayoritaria (54,3\%), frente a los naturales del Magreb, si bien, con los datos disponibles publicados por FRONTEX, Canarias recibe un tercio del total de personas de procedencia marroquí que se desplaza a través de las rutas antes enumeradas. Incluso con pesos que fueron mucho mayores desde finales de 2020, como por ejemplo en el mes de noviembre de ese año, cuando más de cinco mil de esas personas migrantes supusieron el $89,3 \%$ de todas las detecciones de marroquíes registradas. Luego tenemos las procedencias subsaharianas, más repartidas y difíciles de asignar, porque la estadística no ofrece información detallada, aunque las distintas fuentes siempre apuntan a las personas naturales de Senegal, Mali, Costa de Marfil, Guinea Conakri, Gambia y Guinea como protagonistas de esta movilidad, avalado por organizaciones como IOM (2021) y reafirmando los datos ya expuestos.

Fijando intensidades, es importante destacar de manera particular lo sucedido en noviembre de 2020, puesto que se encuentra entre los siete episodios mensuales de mayor impacto en cuanto a número de personas implicadas en las distintas rutas migratorias antes citadas desde enero de 2018, suponiendo además dos quintas partes de la suma total de

\section{Gráfico 1}

Detecciones mensuales en cruces fronterizos ilegales en la Unión Europea según rutas entre enero de 2018 y junio de 2021.

\section{Fuente}

Detecciones mensuales en cruces fronterizos, FRONTEX. Elaboración propia. 
detecciones en ese mes. Hubo que atender en ese corto lapso de tiempo a más de cinco mil migrantes marroquíes $(89,3 \%$ de los magrebíes recibidos en ese mes en la UE a través de estas rutas) y casi tres mil subsaharianos. Ese amplio desplazamiento se realizó en 230 embarcaciones, a bordo de las que llegaron 8.157 personas (casi las mismas cifras que se han contabilizado en todo el año 2021 hasta el mes de agosto).

Se trata del episodio mensual de mayor intensidad registrado en Canarias desde que existe un seguimiento documental de la migración marítima irregular, con sus implicaciones en la operación que tuvo que organizarse para atender esa situación excepcional y con el precedente del mes anterior por encima de cinco mil llegadas. Con todo, entre septiembre de 2020 y enero de 2021, cinco meses, arribaron al archipiélago 21.167 personas, una media de 140 personas diarias. Quedará como la crisis de Arguineguín, pequeño muelle del municipio grancanario de Mogán, donde estuvieron concentradas de manera provisional buena parte de esas personas a falta de un sistema de acogida suficiente y bien articulado para enfrentar este tipo de contingencias. Solo el mes de octubre de 2018 tuvo más intensidad en el entorno peninsular y balear.

Las cifras anteriores hacen referencia a las personas que lograron llegar a algún punto seguro de las islas, muchas de ellas localizadas en alta mar o cerca de la costa y conducidas a puerto. Más fueron las que partieron desde distintos enclaves del litoral africano, puesto que una fracción nunca conocida de las expediciones tienen dificultades de diversa naturaleza y acaban de manera trágica (invisible shipwrecks) (Black, 2021). Hipotermias, deshidratación, ahogamientos o insuficiencias respiratorias, entre otras causas, acaban con la muerte de muchas personas en una de las rutas que se entiende como más peligrosa. IOM a través de su proyecto Missing Migrants estima que, entre 2018 y agosto de 2021, perdieron la vida 1.567 personas en el sector que denomina norte de África, en el entorno geográfico de Canarias, la mitad de las que ha registrado en el continente africano en ese periodo de tiempo ${ }^{4}$. Se trata de una estimación mínima basada en información que facilitan las autoridades nacionales y la que ofrecen los medios de comunicación. Una cifra que al finalizar el año 2021 se aproximará bastante o superará la registrada durante el periodo cuatrienal anterior (2014 a 2017, 1.836 personas).

Caminando Fronteras, colectivo de defensa de los derechos de las personas y comunidades migrantes, eleva notablemente esas cifras. Centrándose solo en 2020, señala 1.851 migrantes fallecidos en 45 naufragios en la ruta canaria, según su Informe Monitoreo Derecho a la Vida 2020 (dicho registro es el doble del obtenido para 2019, 893 fallecidos)5. Sus fuentes son diversas, caso del teléfono que ha habilitado para que las personas interesadas puedan informar acerca de las expediciones, los relatos de las personas supervivientes o de las familias en situación de búsqueda de personas desaparecidas. Según esta organización, la mayor parte de las víctimas quedan en el mar, dado que, por ejemplo, 33 embarcaciones desaparecieron sin dejar rastro. ACNUR, por su parte, cifra en 480 las personas fallecidas de esta manera en 2020 (Defensor del Pueblo, 2021).

Este segundo periodo de notable activación de la afluencia migratoria por vía marítima ofrece algunos elementos contextuales relevantes, que van a influir de manera decisiva en su gestión, incorporando aspectos originales con respecto a etapas anteriores. La pandemia causada por el virus SARS-CoV-2 es el primero y tal vez más significativo, pues-

4 Missing Migrants. Tracking death along migratory routes. Consultado el 19/08/2021. https://missingmigrants. iom.int/

5 Se ha combinado la consulta del Informe citado con la revisión de la información de El País de 29/12/2020 sobre la presentación pública del mismo. 
to que, tanto directa como indirectamente, supone un factor adicional a los existentes como detonante de la movilidad (Black, 2021; CEAR, 2021; Médicos del Mundo, 2021). Y por otra parte, ha condicionado en buena medida la logística de los procesos de acogida, por lo menos hasta que se han ido encontrando fórmulas adecuadas e instalaciones para organizar a las personas que llegan sanas o contagiadas. Ha influido también en las percepciones de la población ya residente, en relación con el efecto que pueden producir las personas que arriban en la esfera de la salud, lo que se suma a la corriente de pensamiento que las asocia con la competencia por los recursos asistenciales o las oportunidades laborales. La COVID-19 ha acabado multiplicando las dificultades ya presentes en las distintas fases de la acogida, e incluso, más allá de la esfera canaria, como afirma Pinyol-Jiménez (2021: 43), ha sido la excusa de algunos países para "endurecer las vías de acceso a su territorio".

Ya se ha señalado que la tendencia ascendente de las cifras de llegadas se comienza a entrever levemente en 2018, pero es en la segunda mitad de 2019, desde agosto de ese año, cuando se produce una secuencia al alza coincidiendo con los meses de otoño e invierno más favorables a la navegación (Godenau, Buraschi y Zapata, 2020). Dicha progresión se interrumpe en febrero, en el arranque de la expansión del coronavirus a escala mundial, e incluso desciende en marzo, coincidiendo con las primeras medidas restrictivas más rigurosas. Es el caso de España y también de Marruecos, así como de otros muchos países que deciden cerrar sus fronteras y se efectúan confinamientos domiciliarios. Se produce además la paralización de buena parte de las actividades económicas no esenciales, viéndose comprometido entonces el horizonte de innumerables personas, familias y hasta comunidades enteras. La primavera sigue siendo incierta, aunque se flexibilizan muchas medidas hacia el inicio del verano, con enorme diversidad de situaciones según regiones y hasta países. Agosto en Canarias ya significa la reactivación de la secuencia que se aplazó en enero: la nueva normalidad trae asimismo una etapa de máxima intensidad migratoria.

De este modo, la pandemia va a condicionar de manera significativa la gestión de la afluencia irregular a través del mar, tanto en lo relativo al proceso de acogida en Canarias, como a las potenciales acciones de devolución de sus protagonistas a los territorios de origen o tránsito, o de derivación a otros recursos localizados en distintos puntos del resto de España. Estrategias habituales en el tratamiento de esta movilidad, sobre todo cuando su intensidad lo ha requerido, que ahora se ven interrumpidas, bien por las decisiones de terceros países en el primer caso, bien por la propia decisión del Gobierno de España en el segundo. Asimismo plantea una dificultad añadida en lo relativo a la habilitación de espacios apropiados para alojar a las personas recibidas, separando, en primer lugar, unas expediciones de otras, y en segundo lugar y cuando proceda, a las personas contagiadas por el coronavirus. Todo ello ha tenido reflejo en la manera en que se ha enfrentado el proceso de acogida, poniendo de manifiesto la debilidad de la capacidad de respuesta existente ante la complejidad de la situación.

Otro elemento de notable importancia que cabe ser reseñado es el marco legal que ha ido acompañando el más reciente proceso de acogida, puesto que incorpora cambios significativos que asimismo inciden en su configuración. Así, por ejemplo, como ya se ha expuesto con detalle en un trabajo anterior, la posibilidad de formular una solicitud de protección internacional por motivos fundamentados ante un juez o jueza de instrucción, anula la posibilidad de internamiento y condiciona la pronta devolución de las personas migrantes, lo que supone, en la mayor parte de los casos, "que se les deba asignar una plaza de primera acogida humanitaria en régimen abierto" (Godenau, Buraschi y Zapata, 2020: 13). Esto implica su alojamiento y la cobertura de sus necesidades básicas, con 
Gráfico 2

Registro mensual de llegadas irregulares a

Canarias a través de la ruta atlántica entre enero de 2018 y agosto de 2021.

Fuente

Informes quincenales sobre inmigración irregular del Ministerio del Interior.

Elaboración propia.

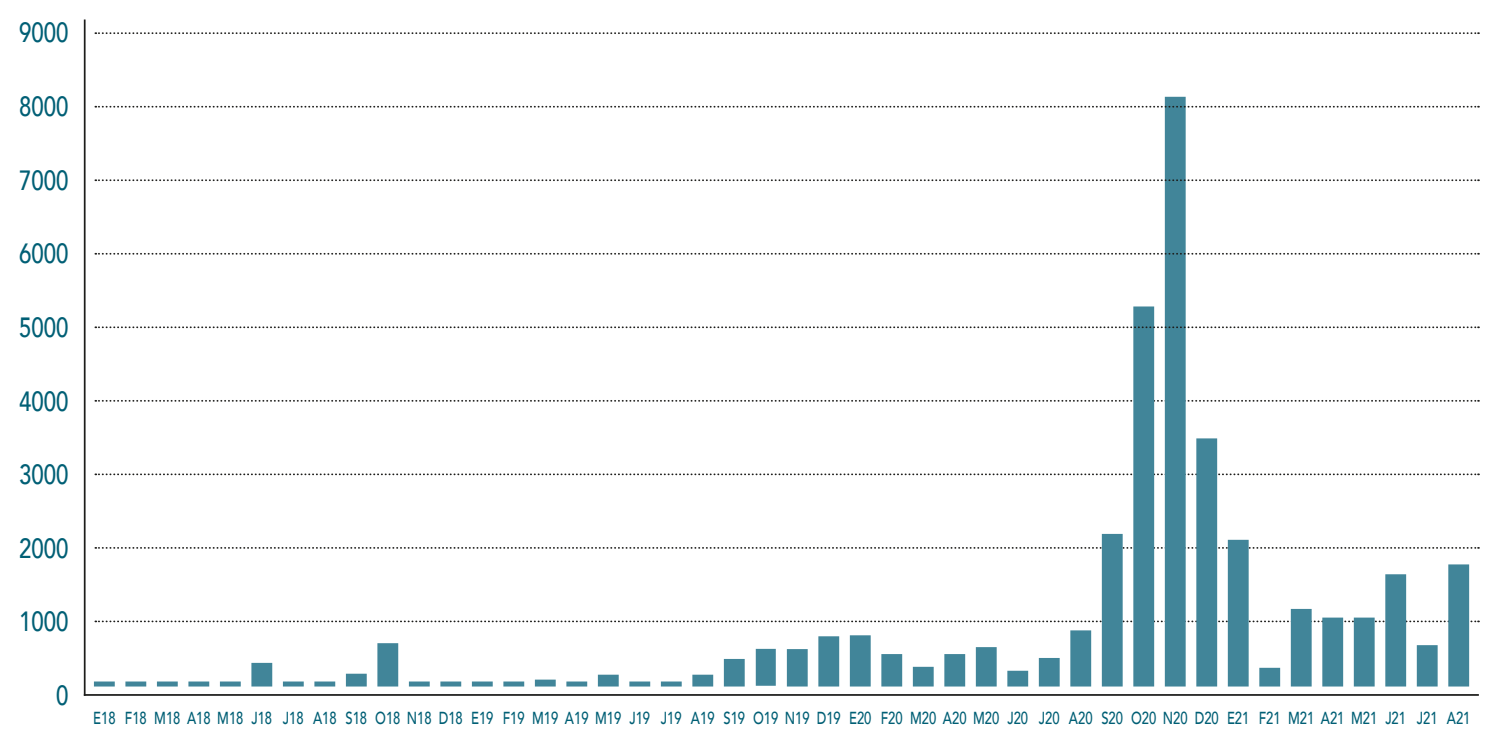

plena libertad deambulatoria, a lo que se responde mediante el desarrollo de un programa que se aplica a cada persona por un tiempo máximo de nueve meses prorrogable a otros seis.

También ha sido significativo el toma y daca casi permanente entre el Gobierno del Estado, la esfera judicial, instituciones como el Defensor del Pueblo o el Diputado del Común en Canarias, así como distintas personas a título particular, colectivos u organizaciones de apoyo a las personas migrantes, en relación con el ejercicio de sus derechos de libre movilidad dentro del Estado español, sobre todo cuando se encuentran en régimen abierto y permanecen en las islas de manera documentada mediante su pasaporte, lo que se ha considerado uno de los principales aspectos de vulneración de los derechos humanos. De forma específica en la primera mitad del año 2021, esto ha impedido el tránsito individualizado hacia la Península de muchas personas acogidas en el archipiélago, salvo casos concretos o en expediciones autorizadas por el Ministerio del Interior y organizadas por el de Inclusión, Seguridad Social y Migraciones a través de entidades especializadas y contratadas por éste. El control policial en aeropuertos ha sido permanente en el periodo apuntado, creciendo las denuncias por las prácticas de perfilamiento racial utilizadas.

Complejidades globales y locales han marcado entonces la nueva etapa de intensificación migratoria, que ha traído hasta el archipiélago a 36.283 personas en 1.190 embarcaciones desde enero de 2018 hasta finales de agosto de 2021, según datos del Ministerio del Interior y puede observarse en el gráfico 2, exactamente una cuarta parte de las recibidas en el conjunto del país, en una secuencia que ha ido equiparando la ruta atlántica a la mediterránea occidental, por lo menos desde la perspectiva de las cifras. Intensidad en las llegadas a las islas "que ha colapsado su capacidad de acogida y que ha obligado a tener que habilitar sobre la marcha diferentes dispositivos provisionales para hacer frente a esta situación" (Defensor del Pueblo, 2021: 7). En ese contexto se desarrolla la respuesta institucional, que es la que se analizará en el siguiente apartado de este documento, centrada en las particularidades que ha experimentado el proceso de acogida migratoria en Canarias. 


\section{Respuesta institucional ante los múltiples retos de la acogida}

Cuando se atiende a la caracterización de la migración marítima irregular sólo a través de las cifras generales, perdemos de vista la amplia diversidad interna que ofrecen las personas que protagonizan esta movilidad en relación con Canarias. Tanto en lo relativo a sus orígenes y procedencias antes de embarcar, como en sus particularidades personales que entrañan el sexo y la edad, las costumbres, cultura y posible confesión religiosa; el grado de conocimiento y la comprensión de las claves para desenvolverse en los nuevos contextos socioterritoriales de residencia, definitivos o temporales; las circunstancias familiares, la experiencia migratoria precedente, las expectativas que se han ido formando a lo largo del proceso, etc. Los sistemas de acogida existentes, muchas veces articulados a partir de la emergencia y en ocasiones con elementos resultantes de la improvisación, no responden siempre a la completa necesidad de las personas que deben recibir. Con todo, se han ido desarrollando distintos conjuntos de recursos que funcionan simultáneamente para atender diferentes perfiles.

A los recursos ya operativos para la recepción y acogida, escasos antes del nuevo proceso de intensificación en Canarias, se tienen que articular otros nuevos en muy poco tiempo, lo que conduce a la proliferación de soluciones de emergencia que se plantean con carácter provisional, pero que, en determinadas oportunidades, se prolongan más allá de lo deseado 6 . El Defensor del Pueblo (2021: 36) sintetiza la imagen del sistema estructural existente en el archipiélago: 2019, 3 centros de acogida con 78 plazas; 2020, 11 centros de acogida integral con 388 plazas. A esto hay que añadir los recursos de emergencia que se habilitan tanto para personas en situación irregular como para solicitantes de asilo, soluciones temporales que se relacionan con el alquiler de hoteles o los espacios cedidos por la Comunidad Autónoma y las entidades locales. A todas luces una respuesta insuficiente para gestionar continuas llegadas a diferentes islas, protagonizadas por personas con características y también necesidades diversas, como ya se ha señalado.

Agosto de 2020 genera el primer aviso importante al apuntar la mayor cifra de llegadas en muchos años: 797 personas en 31 embarcaciones. Sería el preludio de las más de dos mil en septiembre, más de cinco mil en octubre y más de ocho mil en noviembre. Las instalaciones existentes no son suficientes para responder a tales intensidades, considerando además el procedimiento que hay que seguir para la recepción y atención sanitaria, la identificación y filiación, así como la derivación al recurso pertinente en cada caso, tanto en el archipiélago como en la Península si corresponde, puesto que las devoluciones han sido mínimas ${ }^{7}$ durante esta etapa a causa del cierre de fronteras internacionales y las resistencias que el Estado español ha venido encontrando en los países a los que se ha dirigido su demanda (Godenau, Buraschi y Zapata, 2020).

\footnotetext{
6 La respuesta institucional ha sido más amplia que la estrictamente referida a la capacidad de acogida en cuanto a alojamiento y necesidades básicas de las personas migrantes. Este texto se centra sobre todo en esa vertiente, pero se reconocen diferentes esfuerzos por parte de distintas administraciones para ir activando otros recursos y generando soluciones a los múltiples frentes abiertos. Uno de ellos ha sido la capacitación de las policías locales y canaria, que han tenido que colaborar en la esfera de la seguridad ciudadana en los entornos de los dispositivos habilitados.

7 Las devoluciones o repatriaciones durante los últimos meses han sido mínimas y solo se han podido concretar con unos pocos países, caso de Marruecos y Mauritania, siendo escasa la información disponible al respecto. CEAR (2021) apunta 163 a Mauritania en 2020, así como el acuerdo de España con el primer país citado para realizar 80 devoluciones semanales a través de Air Maroc durante los primeros meses de 2021. Según Europa Press (25/04/21), España habría repatriado a 153 personas desde Canarias a sus países de origen en los dos primeros meses del mismo año. Según la Agencia Efe (8/05/21), 509 personas habrían sido trasladadas en 2020, a partir de una respuesta del Ministerio del Interior a diputados del Partido Popular.
} 
La mayor presión y hasta el colapso en algunos casos, se ha registrado en los muelles que han servido de áreas de recepción, siendo paradigmática la experiencia de Arguineguín en el sur de Gran Canaria, donde llegaron a permanecer en un pequeño espigón hasta 2.700 personas migrantes de manera simultánea "en condiciones precarias y de hacinamiento" (Defensor del Pueblo, 2021: 29), más todas las personas e instalaciones provisionales que forman parte de la logística necesaria (seguridad, sanidad, limpieza, traslados, etc.), lo que llevó a la denuncia del enorme deterioro de las condiciones de acogida y detención por parte de distintas organizaciones ${ }^{8}$. A otro nivel ocurrió en distintos recintos portuarios canarios, improvisados Centros de Atención Temporal de Extranjeros (CATE), donde se habilitaron incluso naves de almacenaje desocupadas para aliviar la situación existente al raso y poder gestionar la complejidad añadida por la pandemia, puesto que había que aislar los casos positivos e intentar diferenciar cada expedición. Hasta los últimos días del mes de noviembre de 2019 no fue desalojado de manera definitiva Arguineguín, relevándole Barranco Seco en Las Palmas de Gran Canaria.

En ese lapso de tiempo se recurrió a la solución hotelera como Centros de Estancia Temporal de Inmigrantes (CETI), aprovechando que la actividad turística estuvo detenida muchos meses debido a la COVID-19, abriendo instalaciones de acuerdo con su propiedad en áreas como el Sur de Gran Canaria o Puerto de la Cruz y Santa Cruz de Tenerife en esta última isla. El Ministerio de Inclusión, Seguridad Social y Migraciones dispuso de 5.500 plazas operativas en complejos hoteleros y extrahoteleros de la región. En paralelo fueron habilitándose también otros dispositivos de emergencia para la acogida de las personas menores de edad que iban incorporándose al proceso de custodia y tutela de la Comunidad Autónoma, delegada en determinados casos esta competencia en los Cabildos insulares, siendo gestionados muchos de ellos por distintas organizaciones privadas, sobre todo en las islas de Gran Canaria, Tenerife y Fuerteventura.

El 20 de noviembre de 2020 se presenta la arquitectura del Plan Canarias, a la postre, la fórmula estatal para disponer de plazas de emergencia y soluciones estables de cara a la gestión de la acogida migratoria en el archipiélago (tabla 2). Su estructura se sustenta, sobre todo, en la habilitación de seis instalaciones de propiedad pública vinculadas a los Ministerios de Inclusión, Seguridad Social y Migraciones, del Interior y de Defensa del Gobierno de España, a las que hay que sumar la cesión temporal de una nave en el recinto portuario de La Luz en Gran Canaria por parte de Bankia. Ofrecen inicialmente una capacidad conjunta de 5.900 plazas como recursos de emergencia, a las que se deben añadir 1.100 plazas adicionales de las que dispone el Ministerio de Inclusión en distintas islas y que se encontraban en uso en ese momento. Una revisión posterior, presentada ante el Foro Canario de la Inmigración, fija esa capacidad en 6.301 plazas. En febrero de 2021 se estima que está operativo el sistema concebido, gestionadas las instalaciones por Asociación Católica Española de Inmigrantes (ACCEM), Cruz Roja Española, Fundación Cruz Blanca y Organización Internacional para las Migraciones (OIM u IOM en su siglas inglesas) 9 .

Se trata de dispositivos que se habilitan a partir de una solución de emergencia, como se ha señalado, con la idea de transformarse más tarde muchos de ellos en recursos estables para disponer de 5.350 plazas estructurales, concentrados en tres municipios de las islas de Tenerife (San Cristóbal de La Laguna, 2.600 plazas, 48,6\%), Gran Canaria (Las Palmas,

8 CEAR (2021: 14-16) identificó hasta cuatro importantes irregularidades en Arguineguín: falta de asistencia letrada en llegada; nula identificación y protección de personas con perfiles de especial vulnerabilidad; retenciones ilegales por más de 72 horas; condiciones inhumanas e insalubres en el muelle.

9 En el siguiente enlace puede consultarse la nota de prensa oficial del Ministerio de Inclusión, Seguridad Social y Migraciones: https://prensa.inclusion.gob.es/WebPrensalnclusion/noticias/inmigracionemigracion/detalle/3998 
2.050 plazas, 38,3\%) y Fuerteventura (Puerto del Rosario, 700 plazas, 13,1\%). Se trata de antiguos acuartelamientos y polvorines militares, un colegio público en desuso y una nave en un polígono industrial portuario, que ofrecen distintas localizaciones tanto en el interior de espacios urbanos consolidados como en su periferia. La elección de dichos emplazamientos nunca contó con un proceso previo de información y consulta social, de hecho, la decisión estatal ha sido enormemente contestada desde las localidades en las que se radican los diferentes centros; o campamentos, según la percepción vecinal y se traslada en el lenguaje coloquial y mediático. Su funcionamiento ha generado enorme controversia, tanto dentro como fuera del archipiélago ${ }^{10}$, así como la formulación de múltiples denuncias por violación de los derechos humanos a través de organizaciones como CEAR, Médicos del Mundo, Amnistía Internacional o Human Rights Watch.

Tabla 2 Principales características de los dispositivos del Plan Canarias.

\begin{tabular}{|c|c|c|c|c|c|c|c|}
\hline Denominación & Municipio & Localidad & Titularidad & Tipología & $\begin{array}{l}\text { Recursos de } \\
\text { emergencia } \\
\text { (plazas } \\
20 / 11 / 2020 \text { ) }\end{array}$ & $\begin{array}{l}\text { Revisión } \\
\text { (plazas) } \\
\text { 26/02/2021) }\end{array}$ & $\begin{array}{l}\text { Recurso } \\
\text { estable } \\
\text { (previsión } \\
\text { plazas) }\end{array}$ \\
\hline Colegio León & $\begin{array}{l}\text { Las Palmas de } \\
\text { Gran Canaria }\end{array}$ & $\begin{array}{l}\text { El Lasso } \\
\text { (distrito 1) }\end{array}$ & $\begin{array}{l}\text { Ministerio de } \\
\text { Inclusión }\end{array}$ & $\begin{array}{l}\text { Antiguo colegio } \\
\text { público }\end{array}$ & 300 & 630 & 400 \\
\hline Canarias 50 & $\begin{array}{l}\text { Las Palmas de } \\
\text { Gran Canaria }\end{array}$ & $\begin{array}{l}\text { La Isleta } \\
\text { (distrito 3) }\end{array}$ & $\begin{array}{l}\text { Ministerio de } \\
\text { Inclusión }\end{array}$ & $\begin{array}{l}\text { Antiguo } \\
\text { acuartelamiento }\end{array}$ & 650 & 1.190 & 1.150 \\
\hline $\begin{array}{l}\text { Nave El } \\
\text { Sebadal }\end{array}$ & $\begin{array}{l}\text { Las Palmas de } \\
\text { Gran Canaria }\end{array}$ & $\begin{array}{l}\text { El Sebadal } \\
\text { (distrito 3) }\end{array}$ & $\begin{array}{l}\text { Bankia (cedida } \\
\text { temporalmente) }\end{array}$ & $\begin{array}{l}\text { Nave en polígono } \\
\text { industrial portuario }\end{array}$ & 500 & 500 & 500 \\
\hline $\begin{array}{l}\text { Barranco } \\
\text { Seco }\end{array}$ & $\begin{array}{l}\text { Las Palmas de } \\
\text { Gran Canaria }\end{array}$ & $\begin{array}{l}\text { Barranco Seco } \\
\text { (distrito 1) }\end{array}$ & $\begin{array}{l}\text { Ministerio del } \\
\text { Interior }\end{array}$ & $\begin{array}{l}\text { Antiguo polvorín } \\
\text { militar }\end{array}$ & 500 & & \\
\hline Las Canteras & $\begin{array}{l}\text { San Cristóbal } \\
\text { de La Laguna }\end{array}$ & $\begin{array}{l}\text { Las Canteras } \\
\text { (distrito 6) }\end{array}$ & $\begin{array}{l}\text { Ministerio de } \\
\text { Inclusión }\end{array}$ & $\begin{array}{l}\text { Antiguo } \\
\text { acuartelamiento }\end{array}$ & 1.800 & 1.642 & 2.000 \\
\hline Las Raíces & $\begin{array}{l}\text { San Cristóbal } \\
\text { de La Laguna }\end{array}$ & $\begin{array}{l}\text { Rodeo Alto } \\
\text { (distrito 4) }\end{array}$ & $\begin{array}{l}\text { Ministerio de } \\
\text { Defensa }\end{array}$ & $\begin{array}{c}\text { Antiguo } \\
\text { acuartelamiento }\end{array}$ & 1.450 & $\begin{array}{c}1.200 \\
\text { (hasta } 2.200 \text { ) }\end{array}$ & 600 \\
\hline El Matorral & $\begin{array}{l}\text { Puerto del } \\
\text { Rosario }\end{array}$ & El Matorral & $\begin{array}{l}\text { Ministerio del } \\
\text { Interior }\end{array}$ & $\begin{array}{c}\text { Antiguo } \\
\text { acuartelamiento } \\
\text { utilizado como } \mathrm{CIE}\end{array}$ & 700 & 648 & 700 \\
\hline
\end{tabular}

Nota: Recursos de emergencia (plazas 20/11/2020) anunciados por el Ministro de Inclusión, Seguridad Social y Migraciones durante su presentación pública en la Delegación del Gobierno en Canarias. Revisión (plazas 26/02/2021) coincidiendo con la apertura de todos los dispositivos. Recurso estable (previsión de plazas), una vez se supere la situación de emergencia humanitaria.

Fuente: Ministerio de Inclusión, Seguridad Social y Migraciones. Presentaciones públicas del Plan Canarias (Delegación del Gobierno en Las Palmas de Gran Canaria y Foro Canario de la Inmigración). Elaboración propia.

10 Los pronunciamientos, manifiestos, notas de prensa o comunicados han sido múltiples e impulsados entre los años 2020 y 2021 desde organizaciones como el Centro de Estudios Africanos y el Departamento de Geografía e Historia de la Universidad de La Laguna, Cáritas Diocesana de Canarias, Refugees Welcome, Coordinadora de ONG para el Desarrollo, Asamblea de Apoyo a Personas Migrantes de Tenerife, Plataforma Tercer Sector Canarias o la Red de Migrantes con Derechos de Canarias. Con alcance estatal, entidades tan diversas como Red Acoge, Conferencia Episcopal Española o la Asociación Unificada de Guardias Civiles. 


\section{Municipios canarios con dispo de acogida a personas migrant}
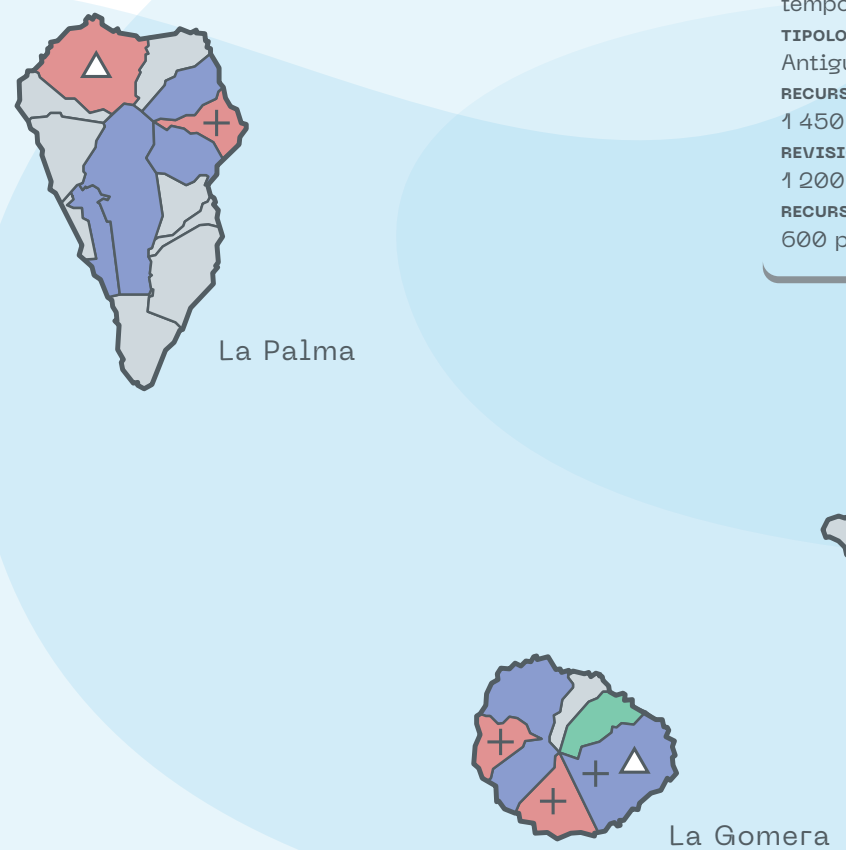

\section{Las Raīces}

MIUNICIPIO

San Cristóbal de La Laguna

LOCALIDAD

Rodeo Alto (Los Rodeos, distrito 4) TITULARIDAD

Ministerio de Defensa (cesiōn

temporal al Ministerio de Inclusión

TIPOLOGÍA

Antiguo acuartelamiento

RECURSO EMIERGENCIA

1450 plazas

REVISIŌNI (02/2021)

1200 plazas

RECURSO ESTABLE

600 plazas
Las Canteras

MUNICIPIO

San Cristóbal de La Laguna

LOCALIDAD

Las Canteras (distrito 6)

TITULARIDAD

Ministerio de Inclusiōn

TIPOLOGÍA

Antiguo acuartelamiento

RECURSO EMIERGENCIA

1800 plazas

REVISIŌN (02/2021)

1642 plazas

RECURSO ESTABLE

2000 plazas

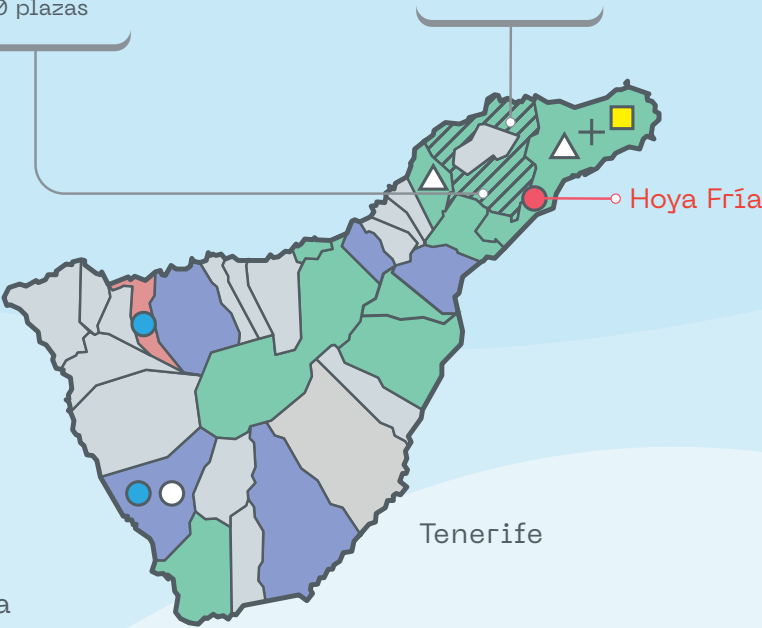

La Gomera

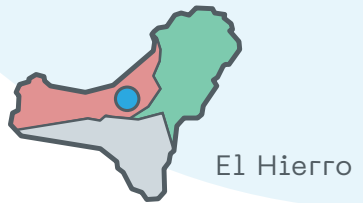

Municipios con dispositivos de acogida temporal del Plan Canarias

Municipios con centros y dispositivos de acogida a personas migrantes menores de edad (CAME y DEMENA)

Otros municipios que pueden estar acogiendo a personas migrantes menores de edad o disponen de centros que pueden hacerlo

Municipios con otros centros de atención temporal a personas migrantes adultas u operativos en un momento anterior
Centro de Internamiento de Extranjeros (CIE)

Centro de Atención Temporal de Extranjeros (CATE)

Otros dispositivos de emergencia o gestión compartida en contextos COVID-19

$\square$ Municipios con recursos para solicitantes de protección internacional

$\triangle$ Municipios con centros de acogida humanitaria integral a personas migrantes

$\triangle$ Municipios con hogares de emancipación рага personas adultas extuteladas 


\section{Nave El Sebadal}

\section{MIUNICIPIO}

Las Palmas de Gran Canaria

LOCALIDAD

El Sebadal (distrito 3)

TITULARIDAD

Cedida por BANKIA

TIPOLOGÍA

Nave en pol. ind. portuario

RECURSO EIMERGENCIA

500 plazas

REVISIÓN (๑2/2021)

500 plazas

RECURSO ESTABLE

500 plazas
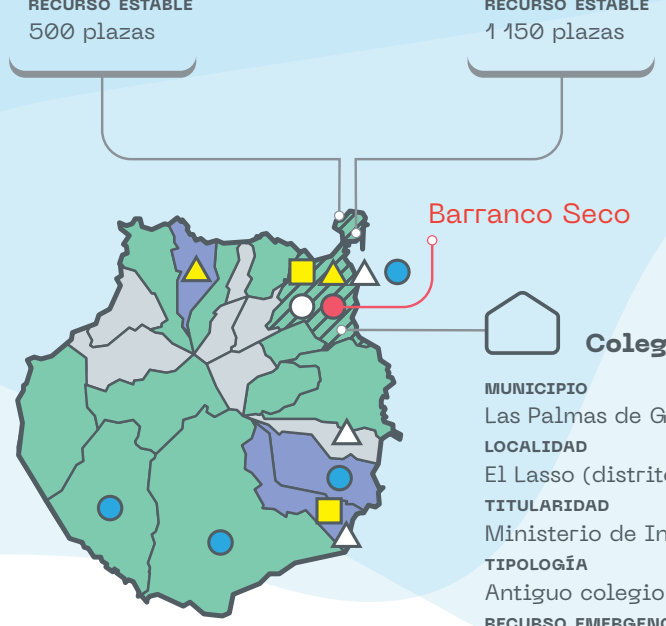

Gran Canaria

\section{Canarias 50}

MIUNICIPIO

Las Palmas de Gran Canaria

LOCALIDAD

La Isleta (distrito 3)

TITULARIDAD

Ministerio de Inclusión

TIPOLOGÍA

Antiguo acuartelamiento

RECURSO EMIERGENIAIA

650 plazas

REVISIŌN (02/2021)

1190 plazas

1190 plazas

1150 plazas

Barranco Seco

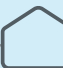

\section{Colegio Leōn}

MIUNICIPIO

Las Palmas de Gran Canaria

LOCALIDAD

El Lasso (distrito 1)

TITULARIDAD

Ministerio de Inclusión

TIPOLOGÍA

Antiguo colegio público

RECURSO EIMERGEIMCIA

300 plazas

REVISIŌN (๑5/2021)

630 plazas

RECURSO ESTABLE

400 plazas
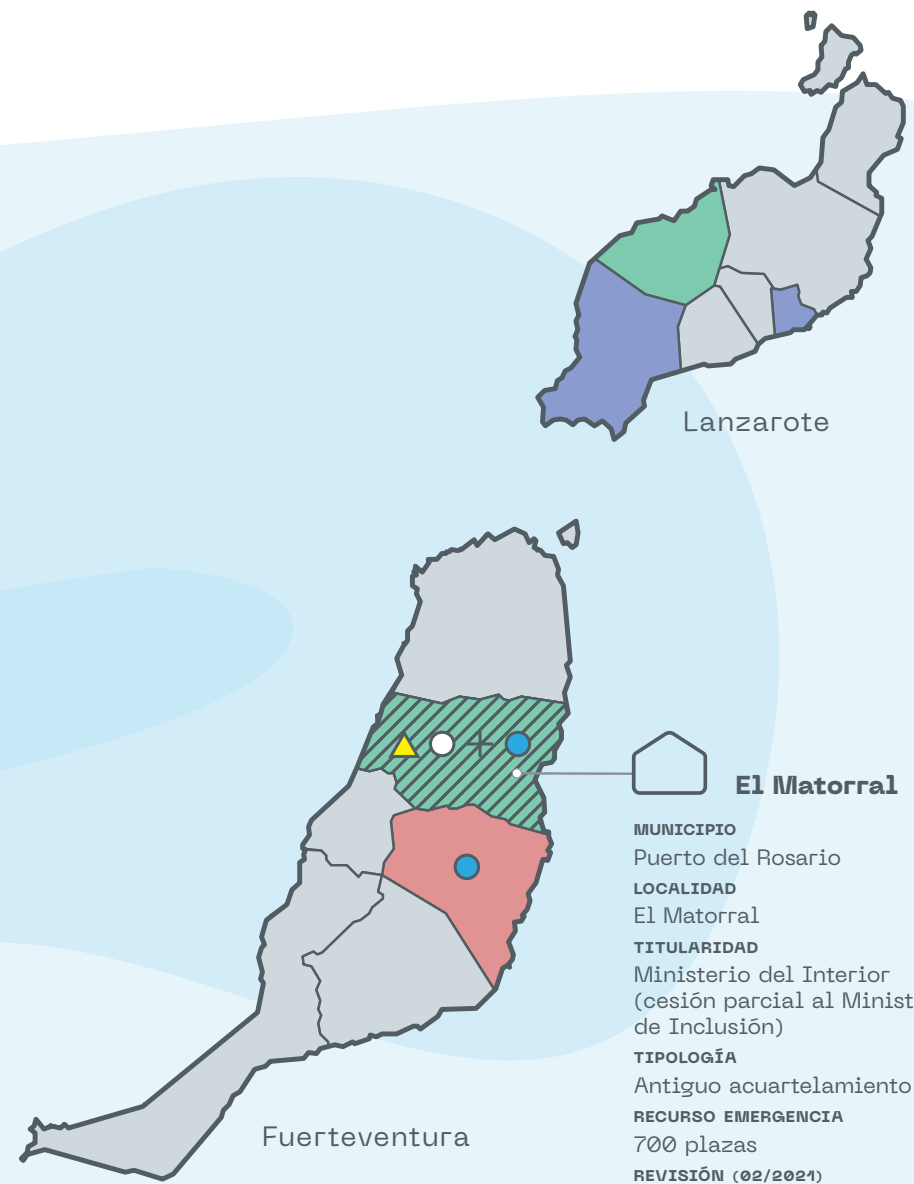

El Matorral

MIUNICIPIO

Puerto del Rosario

LOCALIDAD

El Matorral

TITULARIDAD

Ministerio del Interior

(cesiōn parcial al Ministerio de Inclusiōn)

TIPOLOGIA

Antiguo acuartelamiento RECURSO EMIERGENCIA

700 plazas

REVISIÓN (02/2021)

648 plazas

RECURSO ESTABLE

700 plazas

\section{CRÉDITOS}

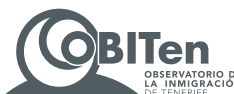

\section{Elaboración}

Observatorio de la Inmigraciōn de Tenerife

\section{Fuentes}

Gobierno de España (Plan Canarias), Gobierno de Canarias, Cabildos

Insulares, Entidades gestoras, CEAR, CRuz Roja y medios de comunicaciōn.

\section{Infografia}

Javier Cabrera DG

Nota: no se cuenta con una única fuente de información que recoja los datos disponibles de los distintos tipos de dispositivos operativos actualmente en Canarias. Barranco Seco en Las Palmas de Gran Canaria ya no se incluye en el Plan Canarias, aunque inicialmente estuvo previsto como recurso de emergencia con 500 plazas. 
A medida que fueron habilitándose, incluso con cierta provisionalidad al principio, dada la premura existente, las diferentes instalaciones recibieron de manera progresiva a las personas alojadas temporalmente en la planta hotelera y extrahotelera de las islas, y casi en paralelo, las que protagonizaron las nuevas llegadas. Sus capacidades previstas fueron alcanzadas casi siempre e incluso superadas en determinadas oportunidades, sobre todo por la reducida opción que ofrecieron las devoluciones y la obstaculización del tránsito individual hacia la Península durante los primeros meses de 2021, con el argumento de los condicionantes derivados de la pandemia, pese a las reiteradas demandas para que se permitiera esa movilidad al no haber motivos legales que la impidieran. Lo cierto es que sí se han producido derivaciones colectivas, aunque organizadas, durante todo ese tiempo, como se ha podido observar en los principales aeropuertos canarios ${ }^{11}$. De hecho, son las que explican la paulatina reducción del volumen de personas acogidas, que según distintas fuentes ha oscilado desde las altas cifras iniciales, las casi 4 mil durante el mes de abril, coincidiendo con una visita de inspección del Defensor del Pueblo, hasta menos de un millar durante el último verano.

Dispositivo de Las Raíces próximo al aeropuerto de Los Rodeos en Tenerife durante su adecuación.

Fuente Vicente Zapata.

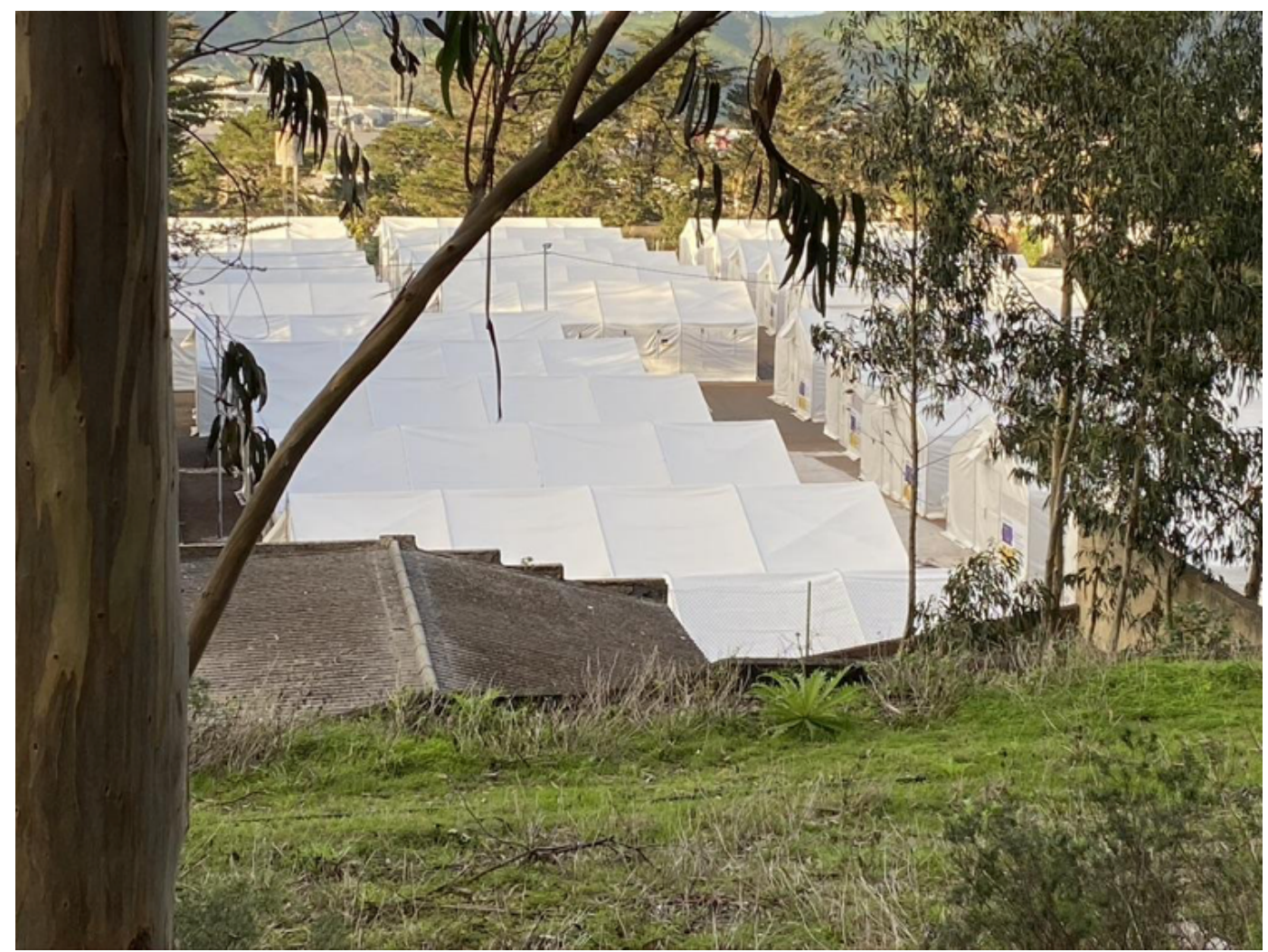

Las dificultades para la devolución a sus países de origen de las personas migrantes recibidas por vía marítima durante los últimos meses, junto a las propias limitaciones que implica la pandemia en cuanto a la utilización de los espacios de internamiento y los brotes de COVID-19, ha provocado una escasa utilización de los dos CIE que actualmente operan en Canarias (Barranco Seco y Hoya Fría) y la transformación del antiguo CIE de El Matorral en un CATE dentro del Plan Canarias. No así de otras instalaciones que se han habilitado para la recepción y atención temporal de las personas recién llegadas en distintas islas,

11 El Ministerio de Inclusión, Seguridad Social y Migraciones, a través de la Secretaría de Estado de Migraciones, reconocía el traslado desde Canarias a la Península, por razones humanitarias, de 6.508 personas migrantes entre los meses de junio de 2020 y abril de 2021, según varios artículos de El País. Febrero fue el mes con más derivaciones, superando las dos mil personas. 
acondicionando lugares como recintos portuarios, estaciones de guaguas, albergues y campamentos, antiguos conventos, etc. Las cuarentenas también han requerido la disposición de alojamientos diferenciados, desde los utilizados para la actividad turística en ese momento vacantes (hoteles medicalizados), naves de almacenaje, residencias escolares, entre otros. Han continuado también activos los recursos de CEAR de primera acogida y acogida temporal para personas solicitantes de protección internacional, así como los de atención humanitaria de carácter integral, tanto en Gran Canaria como en Tenerife, sumando 418 plazas. Y recursos especializados como el CAl para colectivos vulnerables de Santa Cruz de Tenerife, entre otros.

Otra de las particularidades de esta nueva etapa de intensificación migratoria ha sido el incremento de menores en las expediciones: niños, niñas y adolescentes, viajando en solitario o acompañados, una quinta parte de las personas que se desplazan, según el Defensor del Pueblo (2021). Esto hizo que se pasase de 421 menores inscritos en el Registro de Menores Extranjeros no Acompañados de España en diciembre de 2019, el 3,4\% estatal (Fiscalía General del Estado, 2020), a los 2.570 que declaró públicamente el Gobierno de Canarias en junio de 2021. El 79,5\% acogidos en una treintena de dispositivos de emergencia habilitados por la Consejería competente y gestionados por diversas organizaciones, y el resto, atendidos en recursos vinculados a los Cabildos insulares. Con datos del mes de abril de ese último año, el Defensor del Pueblo señaló en comparecencia parlamentaria que se elevaba a 2.776 la cifra de estas personas, la mayor parte todavía pendiente de pruebas de determinación de edad. Esta misma institución comparaba las actuales circunstancias con las vividas en la primera década del siglo, aunque en un periodo más amplio, puesto que, entre 2006 y 2009, fueron acogidos 2.727 menores en recursos de emergencia localizados en distintas islas del archipiélago (Defensor del Pueblo, 2021: 43-44).

El esfuerzo que se hace para acoger a estas personas ha sido y sigue siendo muy importante, puesto que, en este caso, se despliega una auténtica constelación de residencias presentes en todas las islas del archipiélago. El propio Gobierno de Canarias destaca la existencia de un conjunto de 30 dispositivos de emergencia para la atención de menores extranjeros no acompañados en junio de 2021 (DEMENA: 19 en Gran Canaria, 9 en Tenerife y 2 en Fuerteventura), abiertos en su mayor parte entre septiembre y diciembre de 2020, que pueden superar la cuarentena sumando los que se organizan a través de la acción de los Cabildos insulares. Encontrándose otro centenar de centros que funcionan en la región para la acogida genérica de menores, también en disposición de recibir a los recién llegados. Esto supone que casi la mitad de los municipios canarios (40 de 88, el $45,5 \%$ ) estén acogiendo o hayan experimentado alguna experiencia de acogida de menores extranjeros no acompañados o no acompañadas. Estos datos van variando, porque la realidad es cambiante, tanto en lo que se refiere a la incorporación de más personas como a la salida del sistema, por derivaciones a la Península o cumplir la mayoría de edad. En este último caso, también se puede señalar la existencia en varias islas de hogares para jóvenes extutelados (18 a 25 años) por la administración autonómica.

A través de un estudio realizado por ACNUR para el Gobierno de Canarias con información anterior a marzo de 2021, es posible caracterizar mejor a este grupo de personas, particularmente el que se encuentra directamente a cargo de la institución regional, mediante dispositivos de emergencia gestionados por diversas organizaciones especializadas. Aquí reside el 82,1\% del total, 2.108 personas en la fecha antes citada, en su mayor parte varones (99,6\%), de 12 a 17 años $(99,0 \%)$ y procedentes de Marruecos (52,9\%), Mali, Senegal y Gambia. Alojados en 27 centros, en su mayor parte localizados en las islas ya mencionadas, y dentro de ellas, en municipios como San Bartolomé de Tirajana, Las 
Palmas de Gran Canaria, Mogán, La Aldea de San Nicolás y Telde, en Gran Canaria, que agrupa el 70,4\% del total, San Cristóbal de La Laguna, Santa Cruz de Tenerife y El Rosario, en Tenerife, o Puerto del Rosario en Fuerteventura, todos los enumerados con dos o más hogares. El número de niños, niñas y adolescentes por centro es variable y oscila entre casi dos centenares y 7 personas, mostrando una sobreocupación media del 15\%. Una cuestión problemática es la prolongación en el tiempo de la determinación de su edad, mediante las pruebas correspondientes, circunstancia que ha llevado a denunciar casos de convivencia de menores con personas que ya no lo son.

Asimismo el Gobierno de Canarias está recurriendo a las familias inscritas en el programa de acogimiento familiar, con lo que, aparte de los dispositivos antes citados, hay menores, en particular los de más corta edad, que están siendo atendidos por familias de todo el archipiélago. Todo ello tiene implicaciones en otros sistemas públicos, como el educativo, con respuestas concretas ante la necesidad de escolarización de una parte importante de estas personas en cualquier momento del curso académico, lo que supone una adaptación permanente de algunas de sus estructuras. Por lo tanto, antiguos y nuevos programas se conjugan para ofrecer distintas soluciones a las necesidades que surgen en cada momento, como puede ser la iniciativa Unidad Móvil de Atención en Calle (UMAC) de Cáritas, a la que acuden muchas personas migrantes sin hogar o que han quedado fuera de los centros de acogida. Incluso recursos generalistas municipales han tenido que redoblar sus esfuerzos, más recientemente, por la situación de calle de una fracción de las personas acogidas que han abandonado o han sido expulsadas de los dispositivos del Plan Canarias ${ }^{12}$, como podría ser el Albergue Municipal de Santa Cruz de Tenerife o los existentes en Las Palmas de Gran Canaria.

Esta complejidad se ha incrementado todavía más en esta etapa con la incorporación de la ciudadanía a título particular o formando parte de respuestas colectivas y plataformas, ofreciendo recursos propios ante la intensificación de los flujos y las carencias de las soluciones institucionales, ya sea con carácter episódico o más permanente, visible sobre todo en los entornos de algunos de los dispositivos recién abiertos, como el caso de Las Raíces o Canarias 50, entre otros. También ONG y empresas han canalizado ayudas diversas e instituciones como los Cabildos insulares, además de la implicación de ayuntamientos, como por ejemplo los de San Cristóbal de La Laguna y Las Palmas de Gran Canaria a través de distintas líneas de actuación que fomentan varias de sus concejalías ${ }^{13}$. Precisamente en el municipio lagunero se ha acabado constituyendo un Comité Único Permanente para afrontar la gestión de la acogida migratoria, incorporando a los distintos actores que se vinculan con dicho proceso (instituciones en sus distintos niveles, vecindades y tejido asociativo, organizaciones que gestionan los dispositivos, cuerpos policiales, OBITen,

12 Médicos del Mundo (2021) estima que unas 1.000 personas migrantes en Gran Canaria y alrededor de 300 en Tenerife estaban en situación de calle entre finales de febrero y principios de marzo de 2021, la mayor parte de las mismas procedentes de los dispositivos del Plan Canarias, encontrándose en circunstancias de alta vulnerabilidad y viviendo escondidas cerca del mar, en pequeñas cuevas o refugios, en el fondo de barrancos, etc., acudiendo a la mendicidad y/o a los recursos asistenciales generalistas.

13 A modo de ejemplo, se exponen algunas respuestas. El Ayuntamiento de San Cristóbal de La Laguna ha impulsado distintas iniciativas propias y en colaboración con la Universidad de La Laguna, siendo las más importantes la firma de dos acuerdos para la coordinación de las actuaciones que se emprenden desde la municipalidad en relación con el proceso de acogida migratoria, así como para el desarrollo de una estrategia cuya finalidad es contraponer la propagación de los discursos de odio y la proliferación de actitudes xenófobas y racistas. Por su parte, el Ayuntamiento de Las Palmas de Gran Canaria ha promovido el desarrollo de un foro online para analizar y recoger propuestas planteadas por las entidades sociales y las administraciones públicas, relativas a la mejora de los derechos de las personas migrantes que se encuentran en el municipio, también ha cedido temporalmente varios espacios para contribuir al proceso de acogida y ha reforzado su sistema de servicios sociales. De hecho, el antiguo Colegio León en el barrio de El Lasso, tras su reforma, ha sido incorporado al Plan Canarias. 
etc. $)^{14}$. En la capital grancanaria se han celebrado distintas reuniones en la sede de la Delegación del Gobierno.

En lo que atañe a la participación más directa de la ciudadanía, antes señalada, cabe reflejar la amplitud e importancia de la movilización social en esta etapa, incluso mediante la conformación de varias asambleas, plataformas y redes de apoyo que han actuado en distintas islas: Asamblea de Apoyo a Personas Migrantes y Red Migrante, en Tenerife, Somos Red y Red Canaria de Apoyo a Personas Migrantes, en Gran Canaria, Red de Apoyo a Migrantes, en Fuerteventura, pueden ser buenos ejemplos. En ocasiones ha sido la propia vecindad de los entornos de los dispositivos habilitados la que también se ha involucrado en el proceso de acogida -sin desdeñar un número apreciable de personas que ha participado no residiendo en esos mismos lugares-, bien de una manera informal o a través de sus organizaciones representativas, pudiendo citar los casos del Foro por la Isleta en Gran Canaria o de las vecindades de los barrios de Rodeo Alto y Las Canteras en Tenerife. Cabe destacar la interconexión entre algunas de las iniciativa en distintos momentos, con el objetivo de intercambiar experiencias e impulsar acciones conjuntas: "Nos ha cogido de repente, pero está sacando lo mejor de nosotras"15.

Queda patente que este último proceso de intensificación migratoria ha generado una amplia y diversa respuesta en Canarias, aunque no siempre convergente, particularmente institucional y social, más acentuada allí donde se manifiesta el proceso de acogida por estar radicadas las instalaciones que se han ido habilitando de forma progresiva. Varios sistemas y programas funcionan simultáneamente, algunos de los cuales ya venían desarrollando su labor a lo largo del tiempo; otros han emergido ahora, incluyendo iniciativas ligadas al voluntariado comunitario y a la esfera del activismo, logrando organizar interesantes respuestas aunque de incierta sostenibilidad. Las personas migrantes transitan a veces de unas a otras, faltando todavía elementos de coordinación y hasta de coherencia para disponer de un modelo completo y eficaz, alineado con los derechos humanos y que logre integrar adecuadamente todas las aportaciones.

\section{A modo de conclusión y propuesta}

El desarrollo del proceso de acogida migratoria más reciente ha centrado la atención de muchas personas, organizaciones e instituciones a distintos niveles, como se ha expuesto, enmarcado además en el curso del debate sobre el nuevo Pacto sobre Migración y Asilo

14 La Corporación municipal de San Cristóbal de La Laguna ha consensuado distintos acuerdos (noviembre de 2020 y febrero de 2021) para llamar la atención sobre el devenir del proceso de acogida migratoria que tiene lugar en el municipio y exigir a las instancias competentes que se lleve a cabo de la manera más apropiada posible, dentro del marco que establecen los derechos humanos, tanto en relación con las personas migrantes como en lo que atañe a la propia sociedad lagunera, rechazando siempre el recurso a los dispositivos de alta capacidad y enfatizando la necesidad de realizar una distribución más equitativa de las personas migrantes incluyendo su derivación. En mayo de 2021 aprueba de manera unánime una moción para adherirse a la Red Española de Municipios de Acogida de Personas Refugiadas y para el desarrollo de una Mesa de la Acogida a Personas Migrantes y Refugiadas, "para realizar un trabajo estable y permanente que ponga en marcha las diferentes medidas para mejorar la atención y apoyo a esta población".

15 Testimonio del encuentro online celebrado el 31 de marzo de 2021 entre las vecindades de La Isleta, en Gran Canaria, y Rodeo Alto, en Tenerife, para conocerse e intercambiar experiencias en relación con el proceso de acogida migratoria. 
de la Unión Europea ${ }^{16}$, que viene generando una intensa controversia entre sus Estados miembros. Recibir y distribuir personas de manera corresponsable, o por contra, asignar recursos a los territorios fronterizos para limitar los accesos y que allí se detenga la movilidad, favoreciendo asimismo los retornos (Pinyol, 2020), parecen posiciones bastante distantes que determinan, además, diferentes modelos de acogida. En algunos casos muy alejados del planteamiento de la Agenda 2030 y su meta 10.7, que aboga por "facilitar la migración y la movilidad ordenadas, seguras, regulares y responsables de las personas, incluso mediante la aplicación de políticas migratorias planificadas y bien gestionadas".

Existe asimismo amplio consenso acerca del mantenimiento del protagonismo de la ruta atlántica en el complejo mapa de la movilidad africana hacia Europa, con mayor o menor intensidad en cada momento: "es un hecho que el archipiélago canario seguirá soportando de forma continuada una presión migratoria" (Defensor del Pueblo, 2021: 71). Los antecedentes o crisis anteriores, más lo acontecido en los últimos meses, prolongado a lo largo del año 2021, incluso con superior repercusión del trágico balance de muertes que se viene produciendo, demanda el planteamiento de una estrategia global que no solo atienda la emergencia o la excepcionalidad. Y aunque la vocación de las islas parece ser la de mejorar en la función específica de tránsito migratorio, conscientes de la permanencia de estos procesos mientras no se agoten sus determinantes más profundos, la acogida supone todavía una asignatura pendiente que no solo se resuelve con la habilitación de más plazas, siendo ello también esencial.

Así lo ponen de manifiesto múltiples organizaciones, que demandan "redimensionar el programa de acogida humanitaria dotándole de una mayor estructura estable y flexible que desarrolle mecanismos de atención integral e inclusiva y que se pueda adaptar a los diferentes flujos de llegadas" (CEAR, 2021: 29)17. O estructuras colegiadas como el Foro Canario de la Inmigración (2021: 4), que aboga por la "definición de un plan de recepción y acogida con carácter preventivo según escenarios y perspectiva a medio y largo plazo, que implique a las instituciones, a las organizaciones diversas y a la sociedad regional, optimizando los recursos potencialmente disponibles en cada momento". Y en todo caso, "garantizar que todas las instalaciones de acogida temporal cumplan las normas internacionales de derechos humanos" (Red Acoge y otras organizaciones, 2021: 2), aspecto que refuerza el último informe del Defensor del Pueblo (2021: 72), al proponer "un conjunto de instalaciones de carácter permanente que eviten tener que improvisarlas sobre la marcha", reuniendo los elementos esenciales de habitabilidad que permitan "cobijar a las personas con la dignidad que se merecen y contar con los medios personales de asistencia adecuados".

Con todo, parece evidente que el sistema de acogida migratoria existente en el archipiélago ha ido a remolque de los acontecimientos, pese al destacado esfuerzo sin duda realizado, desbordado sobre todo ante la importante intensificación de las llegadas en el tramo final de 2020, dinámica que se ha prolongado incluso con cifras superiores durante el presente año 2021. El Plan Canarias ha pretendido dar una respuesta inmediata a la aco-

16 El nuevo Pacto europeo sobre Migración y Asilo, presentado en 2020 por la Comisión Europea, pone el acento en el control de las fronteras exteriores de la Unión Europea, como mecanismo para limitar el acceso de las personas que se desplazan de manera irregular, apostando por su retorno, obviando "la construcción de un sistema europeo común de asilo integral, así como la búsqueda de propuestas de acceso regular a la UE", reforzando además la narrativa "de la inmigración como una amenaza" (Pinyol-Jiménez, 2021: 45).

17 CEAR asimismo traslada doce propuestas al Senado en la ponencia de estudio para abordar el fenómeno migratorio de forma integral, entre las que se encuentra la de "procurar una estructura estable de acogida humanitaria digna que, además de responder a la cobertura de las necesidades básicas, desarrolle mecanismos de atención integral e inclusiva" (febrero de 2021). (https://www.cear.es/doce-propuestas-migracion-canarias) 


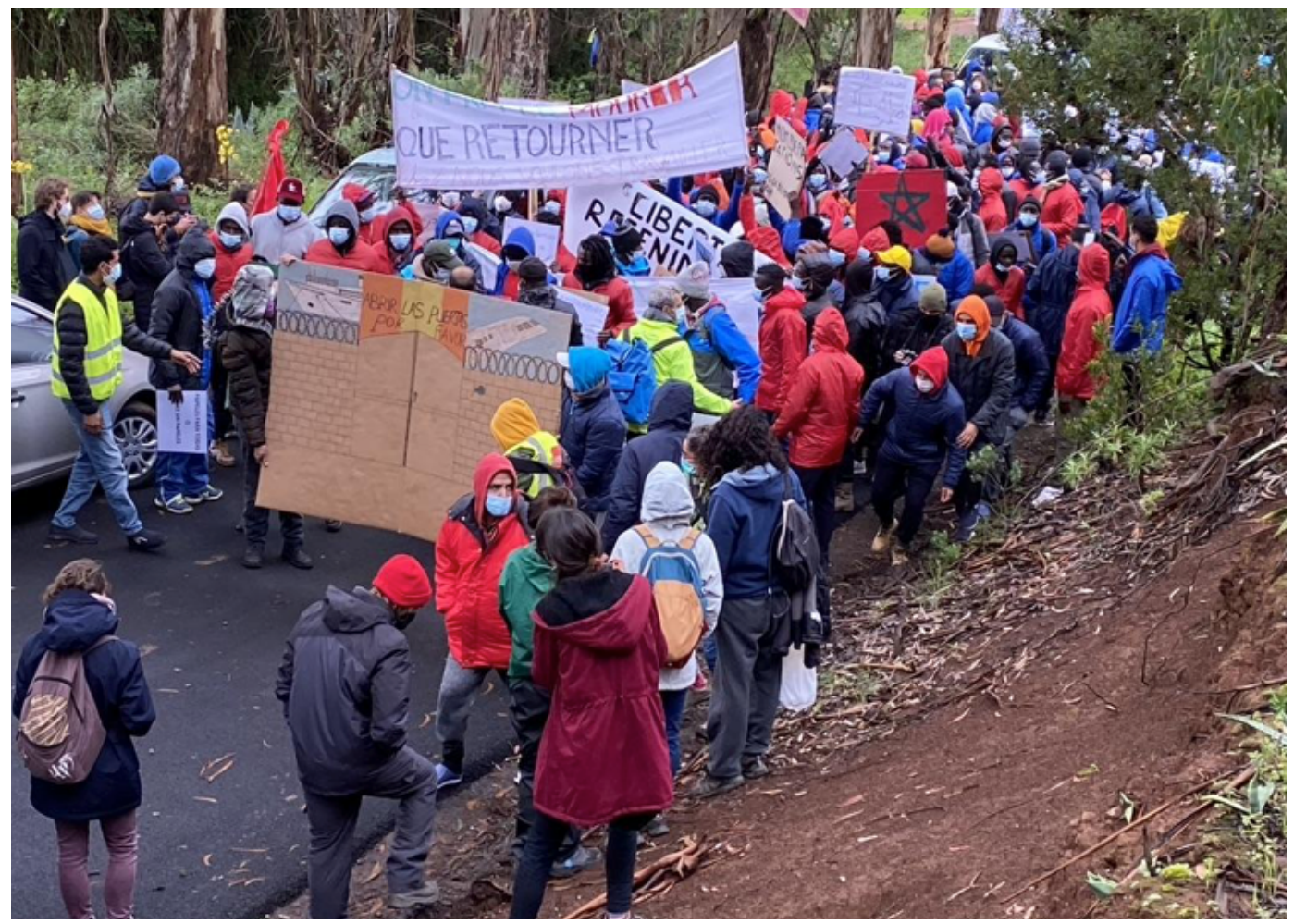

Imagen 2

Manifestación de personas migrantes acogidas en el dispositivo de Las Raíces, junto a grupos de apoyo y ciudadanía en San Cristóbal de La Laguna en marzo de 2021.

Fuente Vicente Zapata. gida humanitaria, pero no constituye el único conjunto de recursos activos, puesto que, a lo largo del tiempo, han ido asimismo habilitándose otros dispositivos para atender unos flujos que ofrecen una creciente diversidad de perfiles, como por ejemplo el amplio número de centros que atienden a las personas menores de edad, a las familias vulnerables, a las solicitantes de asilo, etc. Desde el campamento de Las Canteras, con sus casi dos mil plazas de capacidad máxima, hasta una familia del programa de acogimiento familiar a menores, la casuística es enormemente variada, interviniendo además múltiples actores. Y no consta la existencia de una estrategia global, mucho menos de un modelo específico, adaptado a las particularidades del archipiélago, que hayan sido determinados a partir de un proceso que impulse la confluencia y participación de esos actores.

Ese parece ser el reto fundamental. Dialogar sobre el mejor modelo de acogida migratoria para Canarias, del que se derive la definición participada de una estrategia global que pueda reconducir la actual situación y afianzar, perfeccionándola, la preferente función de tránsito migratorio del archipiélago, puesto que, dadas sus características y limitaciones, parece que no cabe otra posibilidad y responsabilidad. Esa labor se puede desarrollar con las máximas garantías y constituir, además, el punto de inicio de la inexcusable tarea de comprometer, también a las regiones fronterizas europeas, como punta de lanza de los programas de revitalización socioeconómica de las áreas de origen de esta movilidad. Todo ello con enfoque comunitario y acento intercultural (Zapata, 2021a, 2021b), "incorporando a todos los actores relevantes" (Médicos del Mundo, 2021: 40) y procurando la confluencia de las instituciones y el conjunto social, incluyendo a las personas que protagonizan la movilidad, tanto en la dimensión de la acogida propiamente dicha, como en el desafío que supone influir en los factores que impulsan las migraciones, contando con la complicidad de los Estados. Modelo, estrategia y planes de acción, que permitan elevar la mirada desde el fondo del océano hacia las comunidades de partida.

Y aunque esa concreción debe surgir del proceso de diálogo citado, ya hemos adelantado algunas claves que deberían tomarse en consideración, al apostar por "la concepción de 
un sistema de acogida flexible, polivalente en los espacios habilitados, convenientemente repartido por el archipiélago. Sistema en el que cada uno de sus protagonistas desempeñe el papel más adecuado, desde la corresponsabilidad necesaria para gestionar este tipo de estancia que de manera preferente debe ser temporal. $O$ definitiva para las personas que podamos recibir e incorporar con todas las garantías, que serán siempre muchas menos que las que, con fortuna, logran llegar y en su mayoría desean continuar un periplo migratorio inacabado" (Zapata, 2021b: 2). Se apuesta entonces por la participación de todos los municipios canarios, articulando un amplio conjunto de instalaciones de capacidad variable pero reducida, adaptadas a las distintas posibilidades existentes en la escala local, entroncadas con su entorno socioterritorial y hasta empresarial, manteniendo algunos de los actuales dispositivos preparados para gestionar las posibles situaciones de emergencia. Todas las islas deben contar con su correspondiente centro para la estancia temporal migrantes (CETI), evitando así la prolongada exposición de estas personas en los muelles de los puertos canarios.

El marco competencial existente sugiere que todos los actores pueden contribuir, de una u otra manera, al funcionamiento de un sistema estable y concebido para asegurar tanto el bienestar de las personas migrantes como el de las comunidades de acogida. Esto supone generar un espacio permanente de encuentro, diálogo y coordinación, más una estructura de gestión especializada que pueda unificar la actuación de todos los recursos y mecanismos necesarios. Desde las responsabilidades más elevadas de control, planificación y organización a realizar por parte del Estado en colaboración con la Comunidad Autónoma ${ }^{18}$, hasta la gestión más cotidiana que puede acordarse con las corporaciones locales, mucho más conectadas con la realidad de cada lugar: los Cabildos insulares ya tienen dilatada experiencia en la acogida de menores, y algunos de estos y los ayuntamientos, en la promoción de iniciativas convivenciales. Incorporándose entonces las diferentes organizaciones que asumen la tarea de gestionar instalaciones y proyectos diversos, con lo que, existe un amplio campo de mejora para trabajar a partir de una evidente premisa de acción concertada y corresponsabilidad.

Con acento intercultural, además, que enfatice la interacción positiva entre las personas, el respeto a la diversidad y la igualdad, tal y como propone Giménez (2013). Igualdad en su más amplia concepción, para avanzar hacia modelos más completos de acogida e inclusión social -independientemente del tiempo que cada persona migrante se encuentre acogida- que se fundamenten y garanticen por encima de todo los derechos humanos. Comprensión y respeto a la diversidad, considerando que cada persona que llega es única en su singularidad, y así, merece que la atención que se le dispense responda a sus necesidades específicas y tenga en cuenta sus aspiraciones y proyecto de vida. Interacción positiva desde el encuentro y la relación que favorece la participación y permite configurar espacios de colaboración y construcción colectiva, como ya se ha dicho, tanto entre personas como entre organizaciones e instituciones implicadas, esencial para la definición de las mejores respuestas y articular medidas que aseguren el bien común.

18 El Estatuto de Autonomía de Canarias (Ley Orgánica 1/2018, de 5 de noviembre) señala en su artículo 144.3 la posibilidad de que la Comunidad Autónoma participe en las decisiones del Estado sobre inmigración que tengan especial trascendencia para la región, aparte de afianzar sus competencias en atención sociosanitaria, políticas de integración en las esferas social y económica, establecimiento de un marco de referencia para la acogida, etc. 
Para ampliar la información

ASÍN CABRERA, M.A. y GODENAU, D. (dirs.) (2014). Movilidad y Gran Vecindad en las Regiones Ultraperiféricas de la Unión Europea, Santa Cruz de Tenerife: Cabildo Insular de Tenerife.

BLACK, J. (2021). Maritime Migration to Europe: Focus on the Overseas Route to the Canary Islands, Geneva: IOM.

CEAR (2021). Migración en Canarias, la emergencia previsible, Madrid: Cabildo de Gran Canaria.

DEFENSOR DEL PUEBLO (2021). La migración en Canarias. Estudio, Madrid: Defensor del Pueblo.

FISCALÍA GENERAL DEL ESTADO (2020). Memoria elevada al Gobierno de S.M. presentada al inicio del año judicial por la Fiscalía General del Estado, Madrid: Ministerio de Justicia.

GIMÉNEZ ROMERO, C. (2013). Promoviendo la convivencia ciudadana intercultural en barrios de alta diversidad. Ideas y experiencias para una praxis comunitaria. En Hagamos de nuestro barrio un lugar habitable. Manual de intervención comunitaria en barrios, Valencia: CeiMigra, IMEDES y Generalitat Valenciana, pp. 36-57.

GODENAU. D. (2019). Canarias: lugar de llegada y tránsito de la ruta migratoria atlántica hacia Europa. En COMITÉ ESPECIALIZADO DE INMIGRACIÓN, El fenómeno migratorio en España. Reflexiones desde el ámbito de la Seguridad Nacional, Madrid: Presidencia del Gobierno, pp. 155-161.

GODENAU, D. y BURASCHI, D. (2018). Las migraciones marítimas irregulares: las islas en la red de rutas. OBITen Factsheet 2-2018. Recuperado de www.obiten.net

GODENAU, D., BURASCHI, D. y ZAPATA HERNÁNDEZ, V.M. (2020). Evolución reciente de la inmigración marítima irregular en Canarias. OBITen Factsheet 8-2020. Recuperado de www.obiten.net. DOI: https://doi.org/10.25145/r.obitfact.2020.05.

GODENAU, D. y LEÓN SANTANA, J.S. (dirs.) (2012). El nexo fronterizo Sur-Sur. La transnacionalidad migratoria entre Marruecos y Canarias, Santa Cruz de Tenerife: Cabildo Insular de Tenerife.

GODENAU, D. y ZAPATA HERNÁNDEZ, V.M. (coords.) (2005). La inmigración irregular en Tenerife, Santa Cruz de Tenerife: Cabildo Insular de Tenerife.

GODENAU, D. y ZAPATA HERNÁNDEZ, V.M. (coords.) (2007). La inmigración irregular: aproximación multidisciplinar, Santa Cruz de Tenerife: Cabildo Insular de Tenerife.

IOM (2021). Irregular Migration Towards Europe. Western Africa-Atlantic Route, Data Collection Jun-Dec 2020.

MÉDICOS DEL MUNDO (2021). Salud y migración en el Sur de Europa. La salud naufraga en la Frontera Sur, Informe. 
PINYOL-JIMÉNEZ, G. (2021). Migraciones en la Unión Europea en tiempos de sindemia. Anuario CIDOB de la inmigración 2020, pp. 34-48. DOI: https://doi.org/10.24241/ AnuarioCIDOBInmi.2020.34

RED ACOGE y otras organizaciones (2021). Carta abierta por el respeto de los derechos humanos de las personas migrantes en Canarias.

ROJO ESTEBAN, J.F. (2008). La Guardia Civil y el control de la inmigración ilegal hacia Canarias, Cuadernos de la Guardia Civil, 38, pp. 37-65.

ZAPATA HERNÁNDEZ, V.M. (2021a). Acogida migratoria con enfoque comunitario y acento intercultural, Canarias3puntocero.

ZAPATA HERNÁNDEZ, V.M. (2021b). Seamos visibles, Canarias3puntocero.

\section{Cómo citar este artículo:}

ZAPATA HERNÁNDEZ, V.M. (2021). Migración marítima irregular y gestión de la acogida en Canarias. OBITen Factsheet 10-2021. Recuperado de www.obiten.net.

DOI: https://doi.org/10.25145/r.obitfact.2021.01

El Observatorio de la Inmigración de Tenerife es una iniciativa conjunta del Cabildo de Tenerife y la Universidad de La Laguna que surge con vocación de estructura permanente y dinámica para avanzar en el conocimiento científico de los movimientos migratorios. OBITen desarrolla su actividad a modo de centro de recopilación, producción y difusión de información que facilita la opinión cualificada y favorece la toma de decisiones que redunden en una mejor gestión del fenómeno inmigratorio y sus implicaciones.

http://www.obiten.net 